\title{
Conjuntos históricos rurales del área metropolitana de Mérida, Yucatán. Rururbanización entre siglos XX-XXI
}

\author{
Rural historic areas of the metropolitan area of Merida, Yucatan. \\ Rurbanization between XX-XXI centuries
}

\author{
Blanca Paredes Guerrero ${ }^{1}$ (D) y Julio César Pat Canul²
}

\begin{abstract}
Resumen
El concepto rururbanización se refiere al proceso de transformación espacial de asentamientos cuyo origen rural se trastoca debido al crecimiento urbano, el cual, en su irrefrenable expansión, ocupa aquellos ámbitos configurando un híbrido entre lo rural y lo urbano. Este trabajo aborda el estudio de once poblaciones históricas - antiguas haciendas y pueblosubicadas en los bordes de la ciudad de Mérida, Yucatán, en México, para explicar el proceso de rururbanización acelerado en la última década de la región. Los resultados señalan que este proceso tiene como condición previa las políticas en materia de uso de suelo que el gobierno federal y los estatales implementaron décadas atrás para ese fin y que básicamente consistieron en el cambio del régimen ejidal al privado de suelos, los decretos de expropiación y la acción metropolizadora a priori del sector gubernamental en ciudades medias del país. La investigación también concluye y demuestra los efectos que dichas acciones del gobierno tienen sobre el territorio en materia de uso de suelo y forma de ocupación del espacio, y los cambios en el tipo de habitantes y de sus edificaciones, cuyo resultado general se observa en la actual fisonomía rururbana de esos asentamientos.
\end{abstract}

Palabras clave: Rururbanización; Lengua; diversidad cultural; educación intercultural

\begin{abstract}
The concept "rururban" refers to processes of spacial transformation of settlements whose rural origins are disturbed due to an unstoppable urban growth, thus resulting in hybrids between rural and urban. This work studies eleven historical settlements -former haciendas and villages- located on the borderlands of Mérida city in México, to explain the process of accelerated rururbanization in the last decade in the region. The results indicate that one condition of this process were land use policies that implemented by both federal and national governments decades ago. Such policies basically consisted on the change from the communal land regime to the private land, the expropriation decrees and the a priori action towards metropolization medium cities in the country by the government. This investigation also shows -as a
\end{abstract}

Tipología: Artículo de investigación

Recibido: 29/09/2017

Evaluado: $28 / 02 / 2018$

Aceptado: $12 / 04 / 2018$

Disponible en línea: 03/05/2018

Cómo citar este artículo: Paredes-Guerrero, B. y Pat-Canul, J.C. (2018). Conjuntos históricos rurales del área metropolitana de Mérida, Yucatán. Rururbanización entre siglos XX-XXI. Jangwa Pana, 17 (2), 200-216. Doi: http:// dx.doi.org/10.21676/16574923.2387

1. Doctora en Arquitectura. Universidad Autónoma de Yucatán. México. Correo electrónico: bpguerrer@gmail.com. ORCID ID: 0000-0001-9694-2673 2. Maestro en Arquitectura. Universidad Autónoma de Yucatán. México. Correo electrónico: julioc.pat@gmail.com. ORCID ID: 0000-0002-3896-2657 
conclusion-- the effects that such actions by the government have on the territory regarding land use and occupancy of the space forms and the changes in the type of inhabitants and their buildings. Changes that are observable in the current rururban image of these settlements.

Keywords: Rururbanization; Language; cultural diversity; intercultural education

\section{Introducción}

ugares como las antiguas haciendas y pueblos de Yucatán, que podemos hoy considerar conjuntos históricos según la definición de la Unesco (Unesco, 2011), sincretizan espacios y tiempos que se remontan al período prehispánico maya, pasando por el régimen colonial español, por la época independiente, por el siglo XX y los años recién transcurridos del XXI. La configuración heterotópica actual de esos contextos multitemporales es el interés del presente trabajo que expone la relación entre las poblaciones históricas - antiguas haciendas y pueblosy el crecimiento urbano, a través de un acercamiento al proceso de transformación espacial registrado en los casos analizados, así como la perspectiva de los pobladores originales.

Desde su interior, ese conjunto de asentamientos había conservado, al menos durante el siglo pasado, una relativa cohesión sociocultural, arquitectónica y ambiental que se encuentran amenazadas. Hoy muchos ya han sido alcanzados -y otros están en proceso- por la expansión urbana de Mérida, la ciudad capital del Estado, la cual además tiene tradición de ser importante centro regional en el este, sur y sureste de México (figura 1).

A esta conceptuación de los lugares estudiados como conjunto histórico, le atraviesa otra reali- dad que también plantea su lectura conceptual: el fenómeno de rururbanización, que en los últimos años se ha detonado en el área de estudio y la está transformado radicalmente. Por ello, el objetivo de este trabajo es exponer el estado físico-espacial en que se encuentra el avance de dicho fenómeno en el antiguo territorio de 11 casos de estudio y la percepción de los habitantes originales del mismo.

En este texto se expone primero una revisión conceptual acerca del fenómeno de rurubanización. En segundo término, se muestran los antecedentes que señalan el origen y la formación histórica de los pueblos y las haciendas en Yucatán. A continuación, se presenta el diseño de la investigación o la metodología. Los dos apartados siguientes presentan información resultante de la investigación que expone los procesos de transformación físico espaciales determinados por dos procesos diferentes: la expansión urbana y la metropolización. Aquí se observan también las medidas jurídicas implementadas para privatizar el suelo a través de expropiaciones, lo que se concreta en suelos de régimen de propiedad distintos y en cambios de usos de suelo preferentemente de habitación urbana. A continuación, se muestran los resultados de la indagación entre los habitantes acerca de su percepción frente al fenómeno, apelando a la memoria, el sentido de pertenencia o los anhelos de cambio. Para terminar, una discusión y el cierre. 


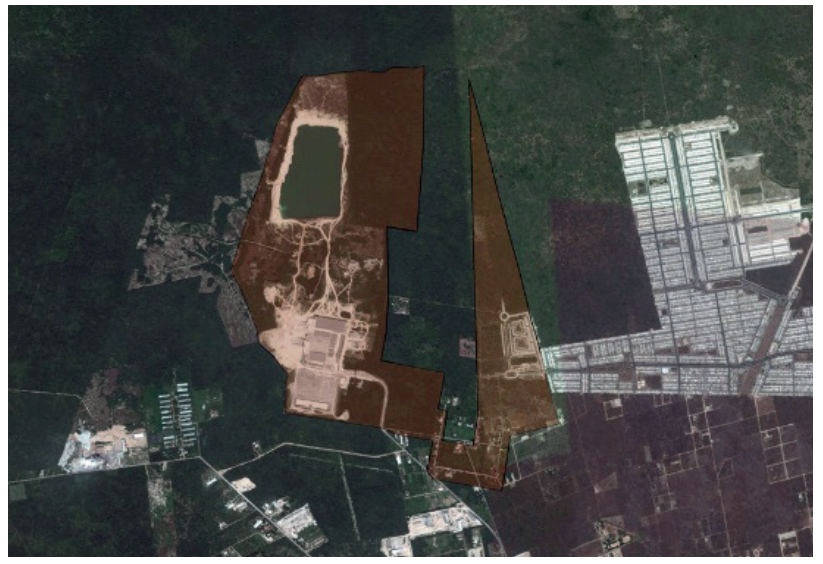

Figura 1. Conjunto histórico de la antigua hacienda San Antonio Hool. Se aprecia cómo la expansión urbana de la ciudad de Mérida, gradualmente ha alcanzado a ese conjunto histórico. En color naranja se señala el territorio cada vez menor y fragmentado del mismo. Fuente: Google Earth.

La información presentada da cuenta de que la distancia entre estos conjuntos históricos y la urbe disminuye a medida que el crecimiento de Mérida se incrementa. La integración a la ciudad de esos ámbitos rurales ocurre a manera de fragmentos, mismos que hoy configuran un archipiélago de espacios urbanos en áreas rurales. Esto nos lleva a referirnos a un territorio que linda entre lo rural y lo urbano, lo rururbano, declarado parte de la zona metropolitana.

Así mismo se puede observar que al interior de las antiguas haciendas y los antiguos pueblos, la estructura de su población también se modificó a favor del incremento de nuevos y distintos grupos sociales que se establecieron y detonaron procesos de inclusión/exclusión, tanto de tipo social como espacial. La mayor presencia de espacios de equipamiento formal e informal genera tensiones tanto internas del lugar como con la ciudad misma.

\section{Rururbanización, dicotomía y síntesis}

Los conceptos urbano y rural, hasta la primera mitad del siglo XX, explicaron, a través de estudios, análisis o conceptualizaciones de entonces, el fenómeno de los espacios habitables y sus relaciones entre los diferentes territorios. De alguna manera, esa dicotomía categórica fue suficiente herramienta de análisis, sobre todo en Latinoamérica, cuando la producción agraria y la población de los países estaba significativamente localizada en el ámbito rural. Sin embargo, la imprecisión conceptual fue planteada entre las décadas de 1960 y 1970 en Inglaterra y Francia (Bauer y Roux, 1976; Phal, 1965) ante lo que se observó como una nueva rururalidad, con la característica en esos países de que se trataba de una migración urbana hacia el ámbito rural - no igual al de América Latina-, proceso que también se entendió como una contraurbanización o exurbanización. Lo cierto es que nuevas dinámicas surgieron en los ámbitos rurales que no podían ser explicados por aquel par conceptual; más bien la dicotomía se sintetizó en lo rururbano.

Cuando la investigación de lo urbano surgió en México, ocurrió sobre todo ante el crecimiento de una de las ciudades más pobladas del planeta: la Ciudad de México. Entonces, el énfasis sobre el fenómeno urbano inició sin detenerse hasta el presente. Uno de los precursores de la materia en este país, Emilio Pradilla, señala en su libro Contribución a la crítica de la teoría urbana que, a mediados de la década de los años sesenta, Francia atrajo a investigadores mexicanos preocupados por el "problema urbano" de Latinoamérica, al cual brevemente caracterizó, involucrando tanto el ámbito urbano como el rural. Las ciudades con su acusado crecimiento 
desigual, inarmónico e inequitativo, y el medio rural con sus profundas transformaciones económicas, políticas demográficas y físicas que, sumadas a la urbanización, señaló el autor, aceleraron sus ritmos debido a la migración campesina hacia la ciudad con la consecuencia de una explosión demográfica urbana y la ampliación de sus fronteras físicas, así como también la modificación de la infraestructura vial y de los servicios mientras que en la periferia se fraccionaban miles de hectáreas de tierra agrícola para localizar zonas industriales y fraccionamientos residenciales (Pradilla, 1987, p. 8). A este autor se sumaron otros planteamientos de lo urbano, convirtiéndose en obras paradigmáticas publicadas en México, como los trabajos de M. Castells, López Rangel, Luis Unikel, R. Segre y Richard Morse (Castells, 1972; López, 1975; Morse, 1973; Segre, 1975; Unikel, 1976).

En la década de los años ochenta del siglo pasado se acuñó el concepto conurbación, el cual, desde la disciplina del urbanismo, expuso los problemas de crecimiento y fusión territorial de ciudades con otras localidades. En 1989 en México el Inegi (2010) definió que conurbación "Es la unión de dos o más localidades, dentro de las cuales por lo menos una de ellas es urbana (de 2500 y más habitantes o es cabecera municipal). La unión se da debido al crecimiento de una o de todas ellas, existiendo una continuidad en su amanzanamiento, entendiendo por "continuidad en su amanzanamiento" el ancho promedio de una calle de la localidad" (p. 4-5). Esta condición de continuidad deja por fuera una multitud de casos de lugares que, aun siendo cercanos a una urbe, no cumplen con este rasgo y por el contrario tienen su propio trazo distinto al urbano y además tienen tierras en su entorno, originalmente destinadas a la agricultura.

Entre el fin del siglo XX y los primeros años del actual, con la proliferación de áreas metropolita- nas y desde las disciplinas de la geografía, e incluso la ecología, aparecen o reaparecen términos propuestos para explicar el fenómeno de la relación entre el espacio urbano y el rural, como deslocalización e incluso difusión urbana, y se repiten las denominaciones de esas áreas como suburbanas, periurbanas, interurbanas, hasta ciudad difusa, asumiendo que todo es urbe (Cañizares, 2007). Este conjunto de conceptos trata de explicar los procesos de la expansión urbana y de las metrópolis a costa de tierras circundantes y el conjunto de modificaciones económicas productivas, ecológicas y sociales en general.

Las transformaciones en estos procesos, para ser explicadas requieren caracterizar lo rural y lo urbano, que a su vez implica, según distintos enfoques disciplinares, criterios muy diferentes que van de lo exclusivamente demográfico (cantidad, dispersión), pasando por la actividad económicaproductiva (agrícola, industrial, servicios, etc.), los usos de suelo (habitacional, comercial, etc.), normativas (áreas metropolitanas, de reserva), físico (densidad de ocupación, uso de suelo, tipo de suelo) y la cultura (urbana o rural) (Capel, 1975).

El concepto de rururbanización resurge en este contexto también denominado postindustrial, sobre todo en países latinoamericanos cuyas ciudades medias transitan hacia la metropolización. Difundido el siglo pasado por Bauer y Roux, el área rururbana se define como una zona próxima a un centro urbano y es sometida al aporte de una población nueva, principalmente de origen urbano, y esa área se caracteriza por la subsistencia dominante de espacios no urbanizados (Bauer y Roux, 1976). No obstante, este concepto explicó una realidad diferente en Francia e incluso en España. Rosselló-Verger (1990) señala dos aspectos centrales para este trabajo: el primero es la ocupación del suelo rural en torno a la ciudad por habitantes de origen urbano y, el segundo, la permanencia del contexto físico rural. 
En las aproximaciones a una definición, el concepto ha sido sujeto a muchas críticas y sus mejores aportaciones tienen que ver con la caracterización de esos ámbitos. En este trabajo se asumen las que tienen que ver con la configuración del espacio habitable, el concepto desarrollado en disciplinas como la arquitectura, que enfocan el proceso de habitar desde la doble relación entre la ocupación del espacio concreto, es decir, el criterio de las estructuras físicas, ambientales y los procesos humanos de habitar, fundamentalmente los modos de vida (Salazar, 2011).

\section{Las haciendas y los pueblos: conjuntos históricos rurales}

Dos ámbitos rurales integraron históricamente la red de asentamientos humanos en la Península de Yucatán: por una parte, la hacienda, institución agraria de larga tradición en América, que tuvo una presencia cuantitativa singular en su etapa productora henequenera, pues se estima una existencia de más de mil haciendas entre los siglos XIX y XX (figura 2); y por otra parte, los pueblos - primero mayas y luego denominados "de indios" durante el período colonial- con una presencia numerosa en la región maya peninsular, lo que convirtió a ambos tipos de asentamientos en fuertes componentes dentro la estructura de poblados de Yucatán (Paredes, 2006).

Sus antecedentes se entrecruzan en el tiempo y en el espacio, surgidos de condiciones adversas para la población maya precolombina. Para esa comunidad, los pueblos tuvieron su origen en el siglo XVI y las haciendas en el XVIII. Los asentamientos mayas originales sufrieron con la conquista española cambios radicales en la estructura territorial de sus espacios habitables debido a que una de las estrategias de la Conquista fue la reagrupación y concentración denominada congregación. Los pueblos de indios, al final del siglo XVII, prácticamente se habían refundado en su totalidad, pues existían 275 pueblos en 1669 (García, 1972).

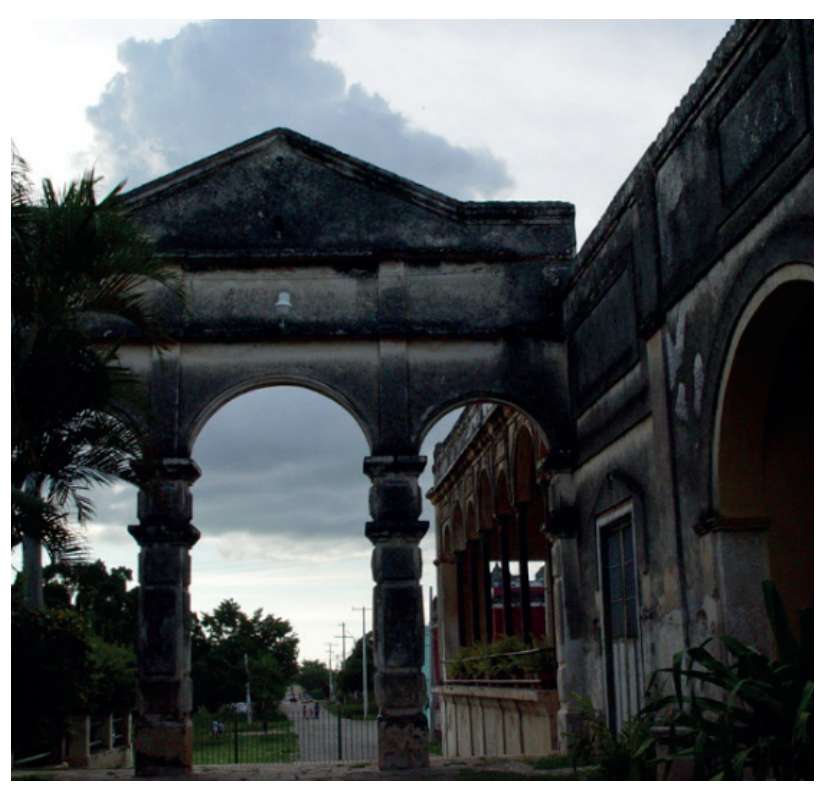

Figura 2. Antigua Hacienda Yaxcopoil. Estructuras antiguas se conservan y mantienen sus pueblos habitados cuando más alejados están de los centros urbanos.

Por otra parte, el germen de la hacienda surge en el siglo XVII con las primeras estancias de españoles -casi siempre de encomenderosdonde estos podían tener ganado, generalmente cerca de ciudades y pueblos de indios, al igual que a lo largo de los caminos. Así establecieron el vínculo Encomienda-Estancia.

En el siglo XVIII, a diferencia de otras regiones de México, ocurrió en Yucatán la transformación de innumerables estancias en haciendas, ocupando más territorio a costa de las comunidades indígenas y constituyéndose en un nuevo tipo de asentamiento en la red peninsular de asentamientos. El objetivo inicial de la hacienda fue fomentar la actividad ganadera - como la estancia- pero pronto incorporó la producción agrícola maicera en respuesta a la creciente 
demanda en ciudades y pueblos de productos agrícolas (Patch, 1976). La estructura de los establecimientos humanos en la península, en el último siglo colonial, estaba compuesta por las ciudades, los pueblos, las haciendas, los ranchos y los caseríos, todos ellos incrementando su población, a excepción de los pueblos. A principios del siglo XIX, las migraciones, desde los pueblos a las haciendas, fueron propiciadas por la legislación agraria que restringió el territorio legal de los pueblos a no más de cuatro leguas cuadradas y en muchos casos a una sola legua, lo que afectó negativamente a sus habitantes básicamente campesinos - obligándolos con ello a abandonar sus poblados (Patch, 1990).

La actividad productivo ganadero-maicera de la hacienda fue sustituida durante la segunda mitad del siglo XIX por otra actividad relacionada con la producción agrícola: el monocultivo del agave henequén, así como su procesamiento agroindustrial y también su comercialización a escala internacional donde fue más conocido como sisal. Este cambio productivo transformó la hacienda en una empresa de aliento más amplio y con un territorio y estructura física de mayores dimensiones (Paredes, 2017). Esa hacienda henequenera se consolidó como un importante centro de población, con motivo de la intensa movilidad de pobladores mayas provenientes sobre todo de los pueblos de indios. Aunque también se poblaron las haciendas de habitantes que los hacendados llevaron de otras regiones del país como los Yaquis, y del extranjero, como cubanos, coreanos, entre otros. Al finalizar el siglo XIX, la población campesina indígena de Yucatán se localizaba prácticamente en su totalidad en el interior de las haciendas henequeneras. De 20767 peones en 1880, aumentó hacía el año de 1900 a la cifra de 80000 peones acasillados (Paredes, 2017, p. 32).
Entre 1915 y 1936 se produjo el fin de la hacienda yucateca, fundamentalmente con dos hechos significativos: la liberación del peonaje, o población acasillada, y de la tierra, hasta entonces en manos dominantemente privadas. Con la Reforma Agraria de 1936, la tierra pasó a manos de los campesinos en calidad de suelo ejidal. Los exhacendados conservaron la pequeña propiedad y prácticamente abandonaron sus posesiones. No obstante, la vida de antiguas haciendas y pueblos continuó y su gente permaneció habitándolos. Prevaleció la actividad productiva henequenera en las tierras ejidales, cuya comercialización fue controlada por el gobierno estatal. Debido a la competencia de los mercados, inició su declive en 1960 cuando prácticamente concluyó la actividad henequenera y el gobierno estatal mantuvo con subsidios a muchos campesinos hasta su cancelación en 1990, cuando el gobierno federal también inició los procesos del cambio de régimen en la tenencia del suelo hacia su privatización.

Esos ámbitos prevalecieron hasta la segunda mitad del siglo XX, la mayoría en condiciones precarias, pero con características ambientales y edificadas singulares, mismas que devienen hoy en conjuntos históricos con diferentes grados de conservación y/o deterioro, siendo quizás lo más valioso en ellos: la presencia de comunidades mayas vivas (tabla 1) que en grado diferente han patrimonializado su contexto y conservado su cultura, pero que están disminuyendo según los censos.

Estos contextos han resguardado una serie de cualidades favorables a la habitabilidad como son la articulación espacial de un contexto, las densidades relativamente bajas de ocupación y edificación, la coexistencia con el medio natural y la cohesión social basada en la cultura maya aún predominante en algunos casos (Figura 3). 
Tabla 1. Estadística sobre población indígena maya en Yucatán

\begin{tabular}{|c|c|c|c|c|}
\hline \multirow{2}{*}{ Entidad } & Año de la información & Población Total & Población Indígena & Respecto al total (\%) \\
\hline \multirow{2}{*}{ Yucatán } & $1990-93$ & 1362540 & 715342 & 52,5 \\
\cline { 2 - 5 } & 2010 & 1955577 & 786113 & 40,1 \\
\hline \multicolumn{4}{|c|}{ Información tomada y modificada de Inegi 1990 y 2010; CDI 1990-2010. } \\
\hline
\end{tabular}

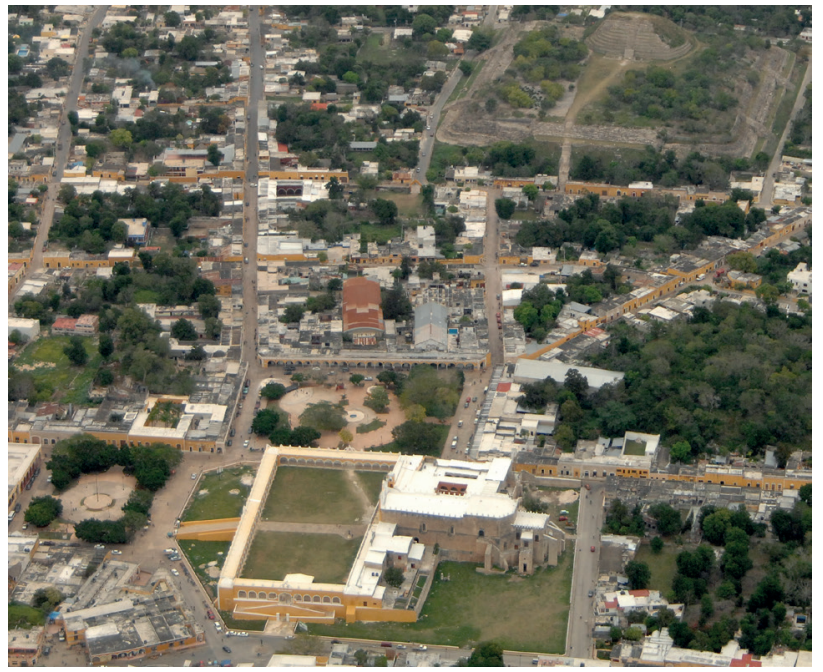

Figura 3. Pueblo de Izamal, Yucatán, donde se sincretizan asentamientos del periodo prehispánico maya (arriba a la derecha la edificación maya Kinich Kakmó) y del colonial (abajo, sobre una plataforma maya, el Convento Franciscano). Fotografía BPG

\section{Materiales y métodos}

\section{Determinación de las unidades de análisis}

Este trabajo aborda el estudio de once poblaciones históricas - antiguas haciendas y pueblosubicadas en los bordes de la ciudad de Mérida, seleccionadas entre las que comparten las características de ser antiguas haciendas o pueblos, de estar relativamente cercanos al anillo periférico de Mérida y que han sido clasificados como centros o subcentros básicos de población con una población entre 100 y 2500 los primeros, y 100 y 1000 los segundos, dentro de la estructura metropolitana oficial de 2005-2010 (Seduma,
2010, p. 18-19).

Las once poblaciones se agruparon según cuatro puntos de localización. Norte: San Antonio Hool, Temozón Norte, Sierra Papacal; Sur: San José Tzal, Texán Cámara, Yaxnic; Oriente Sitpach, Oncán; y Poniente: Chalmuch, Tixcacal Opichén (Figura. 4).

Los criterios para la selección de las 11 comunidades habitadas fueron: 1) casos que abarcan las cuatro latitudes de la ciudad de Mérida: norte, sur, este y oeste; 2) preferentemente que no se encuentren dentro de la mancha urbana; 3 ) que tengan una población mayoritariamente original; 4) que aún se reconozcan los límites físicos del pueblo, en el caso de tener algún desarrollo habitacional cercano; 5) que conserven elementos espaciales y arquitectónicos históricos y, 6) están dentro o muy cerca de límite del municipio de Mérida.

\section{La información documental, estadística y cartográfica}

Dicha información se recogió a partir de la revisión documental de los marcos jurídicos y el régimen de propiedad, y los archivos del Registro Agrario Nacional (RAN) entre los años 1990 hasta 2015, con el fin de registrar en cada caso los procesos ocasionados por las modificaciones al artículo 27 de la Constitución mexicana respecto a expropiaciones, cambio de régimen de propiedad ejidal a privado y su gradual extensión. 
1) El proceso de expansión y metropolización de Mérida

2) Cambios y permanencias de la tenencia de la tierra ejidal y privada

3) Cambios de uso de suelo agrícola a urbano

También, de la información estadística del Instituto Nacional de Estadística y Geografía para determinar las características generales de cada población y de sus viviendas.

1) Demografía

2) Escolaridad, lengua y origen

3) Actividades productivas

4) Desplazamiento de las actividades agropecuarias como el soporte fundamental del sustento familiar

5) Poblaciones comprendidas en la zona metropolitana y la clasificación de las localidades

Adicionalmente, de la revisión de mapas e imágenes satelitales desde 2006 a 2015, para contrastar la información documental y observar cambios de uso del suelo agrícola para identificar nuevos usos industriales y habitacionales urbanos. Con esta información se procesaron las imágenes satelitales de cada localidad en donde es posible observar la cantidad y el tipo de cambio en el uso del régimen de propiedad y el uso de suelo que se ha introducido en esos ámbitos históricos.

1) Expansión urbana sobre suelo rural

2) Usos urbanos: habitacionales, industriales, otros

\section{Trabajo de Campo}

El trabajo de campo tuvo dos tipos de abordaje:

A) Se registraron rasgos físicoambientales, así como la percepción de las comunidades originales frente a los cambios que les han invadido. Para el primer caso se realizaron registros fotográficos y levantamientos arquitectónicos.
1) Introducción de modelos urbanos de ordenamiento del suelo. Morfología (amanzanamiento, lotificación y trazo de calles y caminos)

2) Densidad de ocupación urbana

3) Equipamiento y servicios de tipo urbano

4) Modificación de tipos arquitectónicos rurales por urbano

B) Se entrevistaron a pobladores de las localidades estudiadas con el fin de indagar sobre su percepción respecto a la conservación y el crecimiento urbano, ya sea en los linderos o dentro de los conjuntos históricos. Se consideraron variables como la memoria histórica, el sentido de pertenencia y el grado de contacto e influencia con la cultura urbana, para lo cual la entrevista se diseñó en tres apartados:

El primero fue para identificar la vigencia de la memoria presente entre los pobladores respecto al contexto físico, espacial e histórico y nuevo del lugar: el trazo, la lotificación y el amanzanamiento del poblado, sus edificaciones antiguas, la infraestructura, el equipamiento y los servicios. Esto, tratando de identificar el contraste entre los habitantes en dos situaciones distintas: uno, el caso de los pueblos de los que ya se encuentran rodeados o tienen cerca de sus límites, desarrollos habitacionales urbanos masivos y, el otro, cuando esto aún no ocurre, pero entre los habitantes existe una expectativa.

El segundo, para identificar el arraigo o sentido de pertenencia de los habitantes, vinculándolo con su vivienda, a través de la comparación entre estas con las casas que ofrecen los crecimientos habitacionales de tipo urbano. Entre las características estudiadas están el tamaño del terreno y de la vivienda; la calidad de los materiales constructivos; el diseño y el tipo de espacios interiores (sala, cocina, comedor, cuartos, baños, etc.) y la imagen de la fachada. Así mismo, se indagó sobre la disposición que tendría el habitante de 
cambiar su actual fachada o morada completa por las de tipo urbano ofertadas.

El último apartado se creó para identificar la percepción de esos habitantes acerca de la intensidad de la influencia cultural urbana que reciben. Indagamos en su conocimiento sobre la conectividad que tiene el conjunto histórico a nivel vial y de telecomunicaciones, y los propios habitantes. Por ello, se interrogó acerca del tipo de transporte utilizado para desplazarse a la ciudad; si cuentan con servicios de telefonía fija y móvil; y si cuentan con acceso a Internet, tanto en las viviendas como en el asentamiento en general. Aunque este apartado fue de carácter cuantitativo, pues registró la eficacia de los distintos elementos de conectividad, nos permitió inferencias más amplias.

\section{Resultados}

\section{Crecimiento urbano y la ocupación del suelo rural o ejidal}

En México son comunes los asentamientos sobre todo urbanos- cuyos territorios abarcan dos tipos de suelo: uno de tradición histórica rural, el ejido, y otro el privado-urbano que se yuxtapone al primero. Concretamente, en la ciudad de Mérida y el municipio del mismo nombre, a lo largo del siglo XX y hasta el presente han prevalecido ámbitos rurales históricos - las antiguas haciendas y los pueblos antiguos-y en el contrapunto de ellos, la ciudad, que los abarca en su crecimiento. Ambos son aspectos de un mismo fenómeno relacionado con el recambio de tipos de suelo que ocupan.

La definición de suelo ejidal en México está referido a dos momentos del siglo XX. El primero, en 1917, cuando la Reforma Agraria derivada de la Revolución Mexicana estableció el ejido

3. En su acepción original, "ejido" era el nombre de uno o varios tipos de tierra y de propiedad que integraban el patrimonio de los pueblos como un instrumento de redistribución de la tierra. Por tanto, consistió en dotaciones colectivas inalienables de las tierras relacionadas con los asentamientos, sobre todo rurales, los cuales también se localizaban en los bordes de las ciudades (Alcázar, 2015).

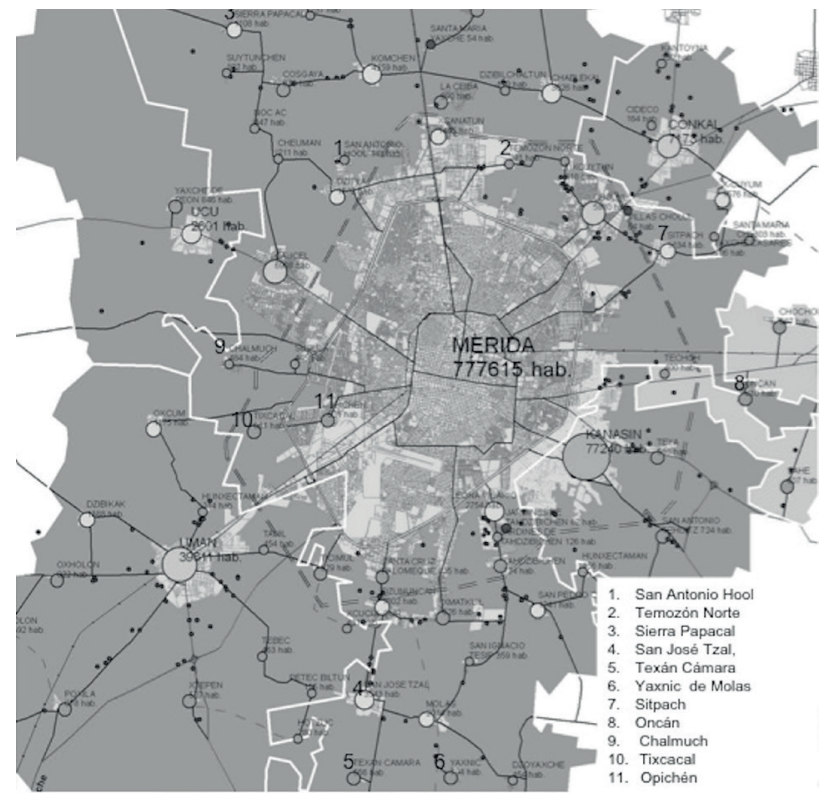

Figura 4. Mapa tomado y modificado de Seduma, 2010. Localización de las once poblaciones objeto de estudio.

El Segundo momento, en 1990, con las reformas constitucionales del articulo 27 en materia de suelo urbano y rural, y sobre todo con las disposiciones incorporadas a la Ley Agraria en 1993, que específicamente señala que el:

Aprovechamiento de áreas y predios ejidales y comunales comprendidos dentro de los límites de los centros de población que formen parte de las zonas de urbanización ejidal y de las tierras de asentamiento urbano en ejidos y comunidades, se sujetará a lo dispuesto en esta ley, en la Ley Agraria, en la legislación estatal de desarro-

de Castilla durante el régimen colonial. Por lo general, eran bosques, dehesas o agostaderos en las afueras de los pueblos (proviene del latín exitus) cuyo uso era colectivo. 
llo urbano, en los planes o programas de desarrollo urbano aplicables, así como en las reservas, usos y destinos de áreas y predios. (Decreto de reforma, 1993, p. 43)

Así, a raíz de la última década del siglo $\mathrm{XX}$, el suelo periférico en todo asentamiento en ese país se ha convertido en el escenario de los procesos de expansión fundamentalmente urbana, cuyos mecanismos y consecuencias son particulares en cada caso, pero los estudiosos han descrito cómo opera el proceso en general en México (Olivera, 2005).

La ciudad de Mérida incorporó de manera significativa el suelo urbano desde la Reforma Agraria de 1936, en cuyos ejidos decretados de pueblos - como Chuburná, Itzimná o Cholul- y de haciendas - como Tanlum y Buena Vista - crecieron colonias urbanas (Paredes y Alejos, 2009).

En 1970, la ciudad inició otra etapa de expansión importante que ha continuado sin detenerse hasta el presente, tanto territorial como demográficamente, a través de la ocupación de suelos rurales ejidales y movimientos poblacionales. Por una parte, los habitantes de Mérida en ese año representaban el $31.9 \%$ del total del Estado de Yucatán. Al término de los años ochenta ese porcentaje se incrementó hasta casi el $40 \%$. Por otra parte, la expansión urbana pasó de 6308 hectáreas en 1970, a 13522 hectáreas en 1980. Es decir, la superficie urbana incrementó más del doble, aproximadamente en 10 años (Inegi, 2010) (tabla 2).

Tabla 2. Crecimiento de la población en la ciudad de Mérida y de su superficie urbana

\begin{tabular}{|c|c|c|c|c|}
\hline Años & Habitantes & Porcentaje de la población estatal & Superficie (en ha) & Densidad (en hab/ha) \\
\hline 1970 & 241964 & 31,9 & 6308 & 38,4 \\
\hline 1980 & 424529 & 39,9 & 8321 & 51,0 \\
\hline 1990 & 556819 & 40,8 & 13522 & 41,17 \\
\hline 1995 & 649770 & 41,9 & $\mathrm{Nd}$ & $\mathrm{Nd}$ \\
\hline 2000 & 703324 & 42,5 & 17280 & 40,70 \\
\hline \multicolumn{5}{|r|}{ Información tomada y modificada de INEGI, 1990 y 2000 } \\
\hline
\end{tabular}

En esos años, el amplio crecimiento urbano coincidió con la incorporación de áreas de "reserva territorial urbana", lo cual sentó el precedente en el Estado, sobre el modelo de expropiación de ejidos de poblaciones cercanas para incrementar la ciudad y favorecer al sector inmobiliario. Es decir, el Estado expropiaba con fines de reserva para transferir esas tierras al sector inmobiliario con su consecuente urbanización (Rivero, 2003). Ese fue, por ejemplo, el caso del pueblo de Caucel, en cuyo perímetro incluía dos antiguas haciendas - Tixcacal y Opichen - ubicadas al poni- ente cercano de la capital, y en esos años ochenta se expropiaron para ser incorporadas a la ciudad mediante el sector inmobiliario urbano (figura 5).

el 23 de diciembre de 1987, se expropió al ejido "CAUCEL", Núcleo Tixcacal y Opichén, Municipio de Mérida, Estado de Yucatán, una superficie de 347-71-51.10 Has., a favor de la Secretaría de Desarrollo Urbano y Ecología, para destinarse a la constitución de una reserva territorial patrimonial para la conservación y el futuro crecimiento de la Ciudad de Mérida. (Decreto primero, 2009, p. 1) 
...Se expropia por causa de utilidad pública una superficie de 610-79-86 Has...de terrenos del ejido “CAUCEL", Municipio de Mérida del Estado de Yucatán, a favor del Gobierno del Estado de Yucatán, para destinarlos a la ampliación de la reserva territorial, desarrollo urbano y la construcción de vivienda y equipamiento (Decreto primero, 2009, p. 2).

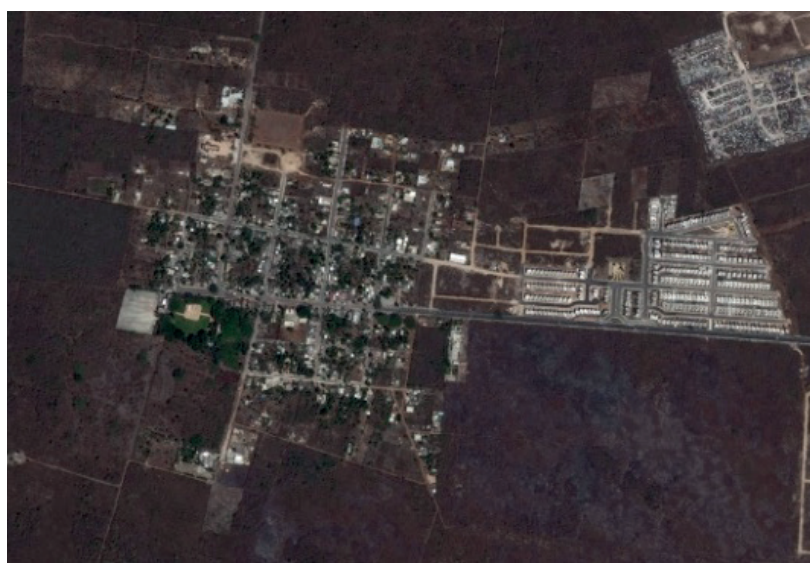

Figura 5. El pueblo de Tixcacal fue expropiado en los años ochenta para ser incorporado a la ciudad. Actualmente se observa la construcción de desarrollos inmobiliarios en los límites del poblado y en el interior de su territorio ejidal. Fuente: Google Earth

Como podemos inferir de la información arriba citada del Inegi, en el año 2000, la ciudad aumentó en un $80 \%$ aproximadamente con 17 280 has., a lo cual contribuyó el mecanismo de expropiaciones y el último cambio a la Reforma Agraria ya señalado, que definitivamente permitió la privatización de la tierra ejidal. La reserva fue ocupada y desbordada entre los últimos años del siglo XX y los primeros del XXI, de manera que hoy se observa en la cartografía una ciudad desagregada y discontinua.

\section{Los conjuntos históricos y sectores metropolizados de Mérida}

El territorio rururbano donde se ubican los conjuntos históricos analizados y la población que los habita, están siendo amenazados por lo que la Unesco en 2011 declaró acerca de los efectos que produce la urbanización rápida e incontrolada:

Suele acarrear fragmentación social y también espacial, así como un grave deterioro de la calidad del medio urbano y las zonas rurales circundantes, lo cual puede ser ocasionado por la excesiva densidad de construcción, el carácter uniforme y monótono de los edificios, la pérdida de espacios y servicios públicos, la inadecuación de las infraestructuras, las lacras de la pobreza, el aislamiento social y al aumento de los riesgos de desastre asociados al cambio climático (Unesco, 2011 párr.17).

Por otra parte, ocurrió el acto metropolizador de áreas rurales concretado en México a partir del año 2005, cuando se delimitaron y reconocieron (Sedesol, Conapo, Inegi, 2007) 56 zonas metropolitanas en el país, entre ellas la ZM de Mérida con cinco municipios constituidos de localidades rurales.

El estudio de los once casos dentro de esa zona que hemos desarrollado, da cuenta de cómo a partir de ese momento la condición de esos conjuntos históricos declarados sectores urbanos metropolitanos por la vía administrativa junto con la liberación de suelo ejidal para la privatización, aceleraron las acciones urbanizadoras y agudizaron la condición rururbana en ese contexto, tanto en términos de su territorio, de su espacio interno, como de su preservación, de lo cual presentamos algunas conclusiones del estudio:

En primer término, el territorio que hoy configura este conjunto de lugares ha quedado estructurado fragmentariamente. Al interior de cada antigua población podemos observar - mediante un análisis diacrónico territorial- el desdibujamiento gradual de la relativa homogeneidad que guardaba el espacio de esos asentamientos. De manera que esos conjuntos - entre los años 2000 
y 2015- han estado transformándose al compás de la expansión urbana y sus impactos se reportan en indicadores como el cambio de tipo de suelo, de ejidal a urbano; de tenencia de la tierra, de propiedad colectiva a propiedad privada; y de uso de suelo, de habitacional y agrícola a urbano habitacional, de servicios o industrial.

En segundo término, el espacio habitable al interior de esos conjuntos presenta condiciones de inclusión cada vez mayor de nuevos y distintos modelos habitacionales y de servicios urbanos, y por otra parte, excluyendo cada vez más los tipos antiguos de habitabilidad rural. Un caso ubicado en el extremo de la exclusión es el de la antigua hacienda San Antonio Hool (figura 6) cuyo territorio ejidal está prácticamente "invadido" en su totalidad por el desarrollo inmobiliario de tipo urbano.

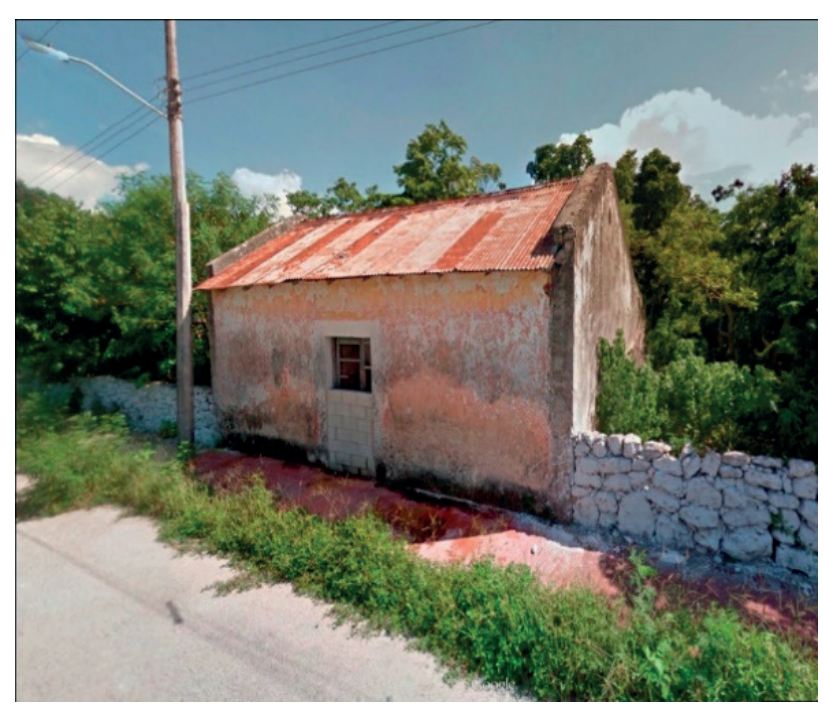

Figura 6. Tipo de habitación tradicional para los trabajadores de la antigua hacienda San Antonio Hool. Fotografía: del autor Julio Pat Canul.

En el intermedio de este proceso surge la simultaneidad y la yuxtaposición en el espacio de formas de habitar rurales y urbanas, donde las primeras pueden tener el carácter de espontáneas e informales y las segundas inducidas o formales, no por ello apropiadas soluciones en el contexto específico.

Las tensiones al interior podemos observarlas en el espacio, en la no consideración del otro, cuando se llega a un lugar preexistente y se modifican patrones del asentamiento como son el tipo de la lotificación, del "amanzanamiento", del emplazamiento y el desplazamiento de la habitación, las nuevas delimitaciones, los servicios, así como también de la modificación de la imagen visual del conjunto.

Respecto a la ciudad, las tensiones ocasionadas son sobre todo de tipo funcional: la fragmentación y dispersión de estos espacios rururbanos que, aún en la lejanía, exigen más de una urbe que no alcanza a dotar todos los servicios necesarios. Es el caso de las comunicaciones a que obligan estos nuevos crecimientos, para lo cual se implementan vías, en ocasiones de manera espontánea, que presionan más aún las áreas urbanas que quedan entreveradas. $\mathrm{Y}$, por otra parte, esas nuevas urbanizaciones localizadas en las cercanías contrastan su realidad deficiente en materia de transporte público y medios de comunicación en general, es el caso del conjunto habitacional "Las Américas", donde algunos de los pobladores prefieren emigrar a la propia ciudad, no obstante, la escaza distancia con la ciudad capital.

En tercer y último término, considerando la condición histórica de los conjuntos estudiados, es relevante la revisión de su preservación y el cambio cultural que ahí ocurre. El análisis realizado ha arrojado la existencia de desigualdades en los niveles de transformación en las distintas zonas que circundan la ciudad. En las extensiones urbanas del oriente, norte y poniente de Mérida, se identificaron con mayor intensidad cambios que avanzan negativamente en materia de preservación, como contraparte de la mayor 
presencia de áreas habitacionales tipo "residencial-privadas", es decir, modelos de urbanización $\mathrm{y}$ arquitectura citadinos; mientras que en la zona sur de dicha ciudad de Mérida, los conjuntos históricos analizados mantienen casi la totalidad de su extensión territorial y muy escasa presencia de acciones de urbanización.

Los deterioros más frecuentes son la desaparición y en repetidas ocasiones el reemplazo de:

- vivienda histórica por vivienda de prototipo urbano

- edificios de equipamiento antiguos por nuevos

- espacios para la recreación y actividades lúdicas

- áreas verdes predominantes sobre la densidad constructiva

- elementos edificados o naturales históricos del espacio colectivo, sobre todo para apertura o ampliación de vías

- visuales y perspectivas del paisaje rural a favor de una imagen urbana

\section{Población, cultura y percepción del habitante original}

La cultura de los habitantes originarios de los conjuntos históricos, como es de esperarse, también se modifica y esto, según planteamos en este trabajo, está relacionado con la percepción que en distintos grados tiene la población respecto al crecimiento urbano y los impactos que está generando dentro y en la periferia de esos conjuntos.

Para conocer esta situación se realizaron encuestas y entrevistas a la población, para identificar en términos cualitativos aspectos como el arraigo al lugar a través de la memoria e historia de las obras edificadas; el sentido de pertenencia e identidad a la comunidad; el grado de influencia de la cultura urbana en su nivel territorial, urbano y arquitectónico.

Del primer aspecto se identificó que existe una memoria y una historia clara entre los pobladores sobre los elementos arquitectónicos representativos en los conjuntos históricos donde habitan, como son el núcleo de edificios principales tanto de las haciendas (casa principal, casa de máquinas, caballerizas, bodegas, etc.) como de los antiguos pueblos de indios (las iglesias, casas ejidales y escuelas que forman parte). Más aún, el arraigo se consolida con el interés manifiesto de esos pobladores por conservar aquellos elementos físico-espaciales que, consideran, definen el lugar que habitan.

En cuanto al sentido de pertenencia e identidad, segundo aspecto indagado, se identificó que existe el deseo de permanecer viviendo en los conjuntos históricos, pues las personas consideran que el modo de vida en sus conjuntos supera por mucho al de la ciudad. Entre las principales razones que los habitantes expusieron para permanecer están una "mayor tranquilidad", el "que no haya contaminación", "la ausencia de tráfico intenso", "la seguridad", todos ellos rasgos asociados a un modo de habitar histórico que les es propio y por tanto coincide con los motivos expuestos por los pobladores.

Respecto a la percepción entre los pobladores del grado de influencia que la cultura urbana tiene sobre estos conjuntos históricos a nivel territorial, urbano y arquitectónico, se observó lo siguiente:

- En la escala territorial, los pobladores no perciben a la ciudad y sus otros puntos de contacto. No obstante, en este estudio se observó que los conjuntos históricos ubicados al 
oriente, norte y poniente de la ciudad de Mérida tienen mayores pérdidas de su territorio que el sur, y por tanto se ha transformado más en dos sentidos: alta presencia de nuevos usos de suelo - como el urbano- y la reconfiguración de los límites de dichos conjuntos.

- A nivel urbano, las transformaciones introducidas a través de crecimientos habitacionales de tipo citadino, desde la percepción de los pobladores no representan una amenaza para sus asentamientos, no creen que ello transforme de manera importante los conjuntos históricos. Sin embargo, consideran que las mejoras al lugar se introducen únicamente en los nuevos fraccionamientos habitacionales de tipo urbano. A pesar de esas opiniones, este estudio identificó que ya existen transformaciones radicales en asentamientos como las antiguas haciendas Temozón Norte y San Antonio Hool, en donde los procesos urbanizadores no ofrecen mejoras a los pobladores originales.

- En el nivel arquitectónico, los pobladores de los conjuntos históricos perciben sus viviendas como elementos de valor, pues a pesar de algunas carencias y desigualdad al compararse con las viviendas de los fraccionamientos o crecimientos habitacionales urbanos que han sido introducidos, están convencidos de que los atributos positivos de sus viviendas son mayores y por ello les representa un alto valor.

En síntesis, la población originaria de los conjuntos históricos, por una parte conserva la memoria e historia, así como el sentido de pertenencia y arraigo a sus espacios habitables, pero, por otra parte, no percibe los niveles de transformación al que está ya expuesta y en pleno proceso de transformación.

\section{Discusión}

En las aproximaciones a una definición, el concepto ha sido sujeto a muchas críticas y sus mejores aportaciones tienen que ver con la caracterización de esos ámbitos. En este trabajo las últimas se asumieron cuando tuvieron que ver con la configuración del espacio habitable, concepto desarrollado en disciplinas como la arquitectura que enfocan el proceso de habitar desde la doble relación entre la ocupación del espacio concreto, es decir, el criterio de las estructuras físicas, ambientales y los procesos humanos de habitar, fundamentalmente los modos de vida (Salazar, 2011). Por ello, estos fueron los énfasis en este trabajo.

Así, para Bauer y Roux, un área rural se considera rururbana cuando cumple dos condiciones o requisitos:

1. Es próxima a centros urbanos y recibe el aporte de una población nueva de origen principalmente urbano, lo cual se traduce en: a) saldo migratorio positivo; b) proporción decreciente de agricultores y artesanos rurales; c) fuerte transformación del mercado inmobiliario.

2. Subsistencia de un espacio no urbanizado dominante.

La construcción de vías de comunicación y los medios de transporte ofrecen condiciones y posibilidades mayores para vincular y transformar localidades rurales con las urbes, en este sentido, en palabras de Bauer y Dezert, rururbanización es la forma de urbanización más representativa de la era del automóvil. (Bauer y Roux, 1976).

Para ser explicada la transformación en estos procesos, se parte de caracterizar lo rural y lo urbano, que a su vez implica, según distintos enfoques disciplinares, criterios muy diferen- 
tes que van de lo exclusivamente demográfico (cantidad, dispersión), pasando por la actividad económica-productiva (agrícola, industrial, servicios, etc.), los usos de suelo (habitacional, comercial, etc.), normativas (áreas metropolitana, de reserva), físico (densidad de ocupación, uso de suelo, tipo de suelo) y la cultura (urbana o rural) (Capel, 1975).

Por otra parte, Rosselló Verger (1990) considera el término rururbanización como "propio de los espacios próximos a las grandes ciudades y áreas metropolitanas, y que consiste en la apropiación del campo por la ciudad", y aclara que destacan dos enfoques para observar el fenómeno:

1. En lo económico estas áreas se caracterizan por la aparición y desarrollo de la agricultura a tiempo parcial como estrategia de supervivencia de la explotación tradicional frente a la competencia de usos de la ciudad; o bien, se desarrolla una agricultura altamente tecnificada, industrializada y competitiva; saldos migratorios positivos; aparición de fenómenos de movilidad diaria, es decir, desplazamientos residencia/lugar de trabajo. 2. Desde el punto de vista espacial, las dos manifestaciones más evidentes de la colonización urbana de las áreas periurbanas que son fruto de los cambios de uso del suelo, consecuencia de la implosión de funciones urbanas, son: por una parte, la implantación industrial por relocalización de establecimientos y polígonos industriales próximos a los grandes ejes de comunicación; por otra, la implantación residencial, es decir, la ocupación del espacio rural por residencias permanentes de población urbana, que diariamente se desplaza a su lugar de trabajo en la ciudad, y también por residencias temporales, que aparecen para satisfacer una demanda de ocio. (Jaume Sebastián, 2000)

El análisis de la situación de espacio relegado y en extinción al que son inducidos los lugares históricos rurales, pocas veces es objetivo en los estudios de los procesos urbanos o metropolitanos, siendo que es muy relevante su condición de espacios habitables con población residente de largo plazo. Observar desde adentro de lo rural el fenómeno, obliga a colocar la mirada en un segmento del conocimiento poco avizorado en las investigaciones que privilegian la lógica urbana, por tanto, a esa caracterización descrita sumamos que se trata de conjuntos históricos, concepto que incorpora la dimensión cultural de manera determinante

\section{Conclusiones}

La complejidad resultante apenas se ha esbozado en este trabajo, sin embargo, hemos procurado dejar cierta evidencia de una realidad altamente contrastante inserta en un proceso de escala global que consiste en la tendencia a la total urbanización del ámbito rural. En general, tanto gobernantes como sus planificadores consideran esto una solución al - empobrecido y carente de servicios - ámbito rural, y sostienen la premisa de que la urbanización dotará de servicios a los pobladores rurales y los incorporará al desarrollo y la modernización. En México, al menos, es como han justificado la entrega de tierras a sectores del sector inmobiliario, de lo cual hemos dado cuenta de solo algunas consecuencias.

Por otra parte, los actos administrativos metropolizadores también se justifican como la alternativa para un buen ordenamiento territorial. Sin embargo, en la última década del siglo XX ha surgido el concepto de agrópolis, que rechaza el enfoque fatalista cuya premisa consiste en que todo nos conduce a la urbanización y plantea un modelo de habitabilidad donde la heterotopía no desaparece, pero sí los componentes, los lugares donde la actualización de los modos de vida no ocurren a costa de la actividad agrícola, del contacto con la naturaleza y de la conservación tanto ambiental como de los contextos históricos, y donde la homogeneidad del espacio no es el objetivo. 


\section{Referencias bibliográficas}

Alcázar, J. (2015). Ley Agraria de 1915 y Ley Agraria vigente: modelos paralelos de tenencia de la tierra. Estudios Agrarios, 58, 161-192

Bauer, G. y Roux, J. M. (1976). La rurbanisation ou la ville éparpillée. Francia: Editions du Seuil.

Binimelis-Sebastian, J. (2000) Sociedad postindustrial y dialéctica campo-ciudad. Aportación al debate a modo de estado de la cuestión. Lurralde: investigación y espacio, 23, 93-113 Recuperado de http://www.ingeba.org/lurralde/lurranet/lur23/ dialecti/dialecti.html.

Cañizares, R.M.(2007).Loscambiosylas estrategias territoriales: hacia una correcta ordenación del territorio en Castilla-La mancha. Revista bibliográfica de geografía y ciencias sociales, 12(704) Recuperado de http://www.ub.es/geocrit/ b3w-704.htm.

Capel, H. (1975). La definición de lo urbano. Revista Estudios Geográficos, 138(139) 265-301.

Castells, M. (1974) La cuestión urbana. Ciudad de México, México: Siglo XXI.

CDI. (2010). Comisión Nacional para el Desarrollo de los Pueblos Indígenas. Ciudad de México, México: Gobierno Federal. Recuperado de: http:// www.cdi.gob.mx/cedulas/index.html.

Decreto No. 1. (2009). Se expropia por causa de utilidad pública una superficie de 610-79-86 hectáreas de agostadero de uso común, de terrenos del ejido Caucel, Municipio de Mérida, Yuc. Diario Oficial de la Federación. 20 t.DCLXVI.

Decreto de reforma. (1993). Ley General de los Asentamientos Humanos. Diario Oficial de la Federación. 15 t.CDLXXVIII.
García-Bernal, M. (1972). La visita de fray Luis de Cifuentes, obispo de Yucatán. Anuario de estudios Americanos, 29, 229-260.

Inegi (1990). XI Censo General de Población y Vivienda. Ciudad de México, México: Instituto Nacional de Estadística y Geografía. Recuperado de www.inegi.org.mx.

Inegi (2000). XII Censo General de Población y Vivienda. Ciudad de México, México: Instituto Nacional de Estadística y Geografía. Recuperado de www.inegi.org.mx.

Inegi (2010). XI Censo General de Población y Vivienda. Ciudad de México, México: Instituto Nacional de Estadística y Geografía. Recuperado de: www.inegi.org.mx.

Inegi (2010). Conurbaciones y fusiones de localidades. Marco Geoestadístico Nacional. México. Instituto Nacional de Estadística y Geografía. Recuperado de:www.inegi.org.mx/geo/ contenidos/geostadística/doc/conur_fusion.pdf.

López-Rangel, R. (1975).Arquitecturay subdesarrollo en América Latina. México. Universidad Autónoma de Puebla.

Morse, R. (1973) Las ciudades latinoamericanas. México: SepSetentas.

Olivera, G. (2005) La reforma al artículo 27 constitucional y la incorporación de las tierras ejidales al mercado legal de suelo urbano en Mexico. Scripta Nova: Revista electrónica de geografía y ciencias sociales, 9(194). Recuperado de: http://www.ub.es/geocrit/sn/sn-194-33.htm.

Pahl, R. (1965). Urbs in Rure. London. London, England: School of Economics.

Paredes, B. (Coord.) (2006). Arquitectura de las Haciendas en Yucatán. México: Fomento Cultural Banamex y Universidad Autónoma de Yucatán. 
Paredes-Guerrero,B. (2017). Haciendas de Yucatán. Historia de la arquitectura rural. Mexico. UADY-CONACYT.

Paredes, B. y Alejos, Y. (2009). Metropolización de Mérida y la hacienda. Co-ocupacion del mismo territorio. En Salazar, G. (Coord.), Modernidad, patrimonio, tecnología y diseño. Estudios del espacio habitable (pp. 64-73) México: Universidad Autónoma de San Luis Potosí.

Patch, R. (1976) La formación de estancias y haciendas en Yucatán durante la Colonia. Revista de la Universidad Autónoma de Yucatán, 116, 95-132.

Patch, R. (1990). Descolonización, el problema agrario y el origen de la Guerra de Castas 18121847. En Baños, O. (Ed.) Sociedad, estructura agraria, y Estado de Yucatán (pp. 45-89) México: UADY

Pradilla-Cobos, E. (1984). Contribución a la crítica de la "teoría urbana". Del "espacio" a la "crisis urbana”. México: UAM-X.

Rivero, L. (2003) La aportación de terrenos ejidales y comunales al desarrollo urbano. Estudios Agrarios, 24, 131-173.
Rosselló-Verger, V.M. (1990). Geografía Humana del País Valenciano. Barcelona, España: Oikos-Tau Sedesol, Conapo, Inegi. (2007). Delimitación de las zonas metropolitanas de México 2005. Ciudad de México, México.

Seduma (2010). Jerarquía de las Localidades (2008 2010) y Población del Estado de Yucatán (2005 - 2010). Recuperado de http://www.seduma.yucatan.gob.mx/ desarrollo-urbano/zona-metropolitana-merida.php.

Segre, R. (1975). Las estructuras ambientales de América Latina. México: Siglo XXI.

Unesco (2011). Recomendación sobre el paisaje urbano histórico, con inclusión de un glosario de definiciones. Recuperado de: http://portal.unesco. org/es/ev.phpURL_ID $=48857 \& U R L \_D O=D O \_$ TOPIC\&URL_SECTION=201.html.

Unikel, L. (1976). El desarrollo urbano de México. Ciudad de México, México: El Colegio de México.

Salazar, G., (2011). Las lecturas del espacio habitable. En Zalazar, G., Azavedo, E., Ettinger, C., Paredes, B. y Torres, L. (Ed.), Lecturas del Espacio habitable (pp. 2-18). Ciudad de México, México: UASLP-Conacyt. 